DOI:10.5216/cab.v15i1.12233

\title{
COMPARAÇÃO ENTRE OS SISTEMAS AUTOMATIZADO E CONVENCIONAL DE CRIOPRESERVAÇÃO DE SÊMEN BOVINO
}

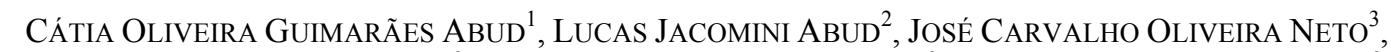 \\ Margot Alves Nunes Dode ${ }^{3}$, José Robson BezerRa SERENO ${ }^{3}$, CARlos Frederico Martins ${ }^{3}$, \\ ${ }^{1}$ Médica Veterinária autônoma, Goiânia, GO, Brasil. catiaogvet@hotmail.com \\ ${ }^{2}$ Professor da Universidade Federal Rural da Amazônia, Paraupebas, PA, Brasil \\ ${ }^{3}$ Pós-Doutorando da Universidade de São Paulo, Piracicaba, SP, Brasil. \\ ${ }^{3}$ Pesquisadores Doutores da EMBRAPA - Cenargen, Brasília, DF, Brasil.
}

\begin{abstract}
O objetivo deste estudo foi comparar a eficiência do sistema automatizado (curva de resfriamento controlada eletronicamente) de congelação de sêmen bovino versus o sistema convencional (curva não controlada) por meio dos parâmetros de qualidade e viabilidade espermática no período pós-descongelação. $\mathrm{O}$ sêmen de quatro touros azebuados adultos foram criopreservados simultaneamente em meio tris, gema e glicerol $7 \%$. A avaliação computadorizada do sêmen descongelado detectou os seguintes parâmetros: MP 56,50 $\pm 22,25 \%$; VAP $34,77 \pm 4,25 \mu \mathrm{m} / \mathrm{s} ; \quad$ VSL $28,17 \pm 4,25 \mu \mathrm{m} / \mathrm{s} ; \quad \mathrm{VCL}$ $58,45 \pm 6,85 \mu \mathrm{m} / \mathrm{s}$; STR $82,00 \pm 2,31 \%$; LIN 49,50 $\pm 3,32 \%$, para o sistema automatizado e MP. $57,00 \pm 13,11 \%$; VAP $25,75 \pm 1,66 \mu \mathrm{m} / \mathrm{s} ; \quad$ VSL $23,32 \pm 1,99 \mu \mathrm{m} / \mathrm{s} ; \quad$ VCL $63,32 \pm 1,79 \mu \mathrm{m} / \mathrm{s} ; \quad$ STR $\quad 82,25 \pm 3,59 \mu \mathrm{m} / \mathrm{s} ; \quad$ LIN $50,00 \pm 4,97 \mu \mathrm{m} / \mathrm{s}$ para o sistema convencional. Os valores

médios das avaliações de integridade de membrana plasmática e integridade acrossomal foram de $54,72 \pm 12,55 \%$ e $36,13 \pm 22,20 \%$ para o sistema automatizado e $53,22 \pm 13,22 \%$ e $47,26 \pm 5,74 \%$ para o sistema convencional, respectivamente. Com os parâmetros avaliados foi possível identificar que não houve diferença estatística entre os sistemas de criopreservação. Desta forma, a escolha do método de criopreservação do sêmen bovino para utilização direta na propriedade fica a critério do técnico responsável, que deverá se basear na realidade de cada propriedade. Para tanto, sempre se deve considerar que o sistema convencional pode trazer mais variações que o sistema automatizado que, apesar do custo do equipamento, pode garantir repetibilidade nos resultados e consequente qualidade do sêmen bovino criopreservado.
\end{abstract}

PALAVRAS-CHAVE: biotecnologia; criopreservação; curvas de congelação; inseminação artificial.

\section{COMPARISON BETWEEN THE CONVENTIONAL AND AUTOMATED SYSTEMS OF SEMEN BOVINE CRYOPRESERVATION}

The objective of this study was to compare the efficiency of bovine semen cryopreservation using the controlledrate freezing machine versus the conventional method (uncontrolled curve) by the parameters of sperm quality and viability in post-thaw period. Semen from four adult crossbreed bulls was cryopreserved in Tris-yolk-glycerol medium. The computer assisted analysis of thawed semen detected the following results: PM 56.50 $\pm 22.25 \%$; VAP $34.77 \pm 4.25 \mu \mathrm{m} / \mathrm{s} ; \quad$ VSL $\quad 28.17 \pm 4.25 \mu \mathrm{m} / \mathrm{s} ; \quad$ VCL $58.45 \pm 6.85 \mu \mathrm{m} / \mathrm{s} ;$ STR $82.00 \pm 2.31 \%$; LIN $49.50 \pm 3.32 \%$, to automated system and PM 57.00 $13.11 \%$; VAP
$25.75 \pm 1.66 \mu \mathrm{m} / \mathrm{s} ; \quad$ VSL $\quad 23.32 \pm 1.99 \mu \mathrm{m} / \mathrm{s} ; \quad$ VCL $63.32 \pm 1.79 \mu \mathrm{m} / \mathrm{s} ; \quad$ STR $\quad 82.25 \pm 3.59 \mu \mathrm{m} / \mathrm{s} ; \quad$ LIN $50.00 \pm 4.97 \mu \mathrm{m} / \mathrm{s}$ to conventional cryopreservation system. The results of plasma membrane and acrosome integrity evaluation were $54.7 \pm 12.55 \%$ and $36.13 \pm 22.20 \%$ for the automated system and $53.22 \pm 13.22 \%$ and $47.26 \pm 5.74 \%$ for the conventional system, respectively. The parameters evaluated demonstrated that there was no statistical difference between the cryopreservation systems. Thus, the choice of the bovine semen cryopreservation method to be used on a farm is a responsibility of the technician, 
and should be based on the reality of each farm. Therefore, it is always necessary to consider that the conventional system of bovine semen cryopreservation can vary more than the automated system, which, despite the cost of the equipment, can ensure repeatability of the results and consequent quality of cryopreserved bovine semen.

KEYWORDS: artificial insemination; biotechnology; bovine sperm; cryopreservation; cryopreservation curve.

\section{INTRODUÇÃO}

A inseminação artificial é a biotecnologia que causa maior impacto nos programas de melhoramento genético de bovinos, resultado da sua eficiente forma de dispersão de genes de animais de mérito genético no rebanho. No entanto, a eficiência da inseminação artificial com sêmen congelado consiste em um adequado processo de criopreservação dos espermatozóides e consequente avaliação da sua viabilidade celular.

A maioria dos métodos de criopreservação de espermatozóides de mamíferos ainda consiste de vários passos não fisiológicos, que envolvem a adição hipertônica de um agente crioprotetor permeável (ACP), resfriamento, aquecimento e a remoção do crioprotetor (1). Esses passos possuem relação com a estrutura funcional das membranas espermáticas e metabolismo celular (2).

Vários aspectos da criopreservação espermática têm sido estudados, tais como a composição química dos diluentes e seus efeitos sobre a membrana plasmática, limites de tolerância osmótica, condutividade hídrica e a permeabilidade dos crioprotetores (3). Esses estudos sugerem que os espermatozóides de cada espécie têm diferentes propriedades criobiológicas, bem como apresentam variação quanto à sensibilidade, manipulação (pipetagem e centrifugação), tolerância osmótica e sensibilidade ao resfriamento $(4,5)$.

Atualmente, muitas fazendas recorrem ao congelamento de sêmen de seus reprodutores, com a finalidade de facilitar o manejo dos animais na fazenda, bem como para manter estocada genética de importância para o rebanho e utilizá-la em estações de monta. Considerando que o procedimento de congelamento utilizado nestes casos pode interferir na viabilidade final do sêmen, este trabalho teve como objetivo comparar a eficiência do sistema automatizado (curva de resfriamento controlada eletronicamente) de congelação de sêmen bovino versus o sistema convencional (curva não controlada) por meio dos parâmetros de qualidade e viabilidade espermática no período pós-descongelação.

\section{MATERIAL E MÉTODOS}

Foram utilizados quatro touros da raça Nelore Mocho, com idade superior a 24 meses, provenientes do rebanho da Embrapa Cerrados localizada em Planaltina - DF. O esgotamento das reservas espermáticas extragonadais foi realizado uma semana antes das coletas para criopreservação de sêmen, pela técnica de eletroejaculação, com objetivo de renovar o estoque de espermatozóides na cauda do epidídimo.

Imediatamente após a coleta por eletroejaculação, o sêmen foi levado ao laboratório onde o volume foi determinado por tubo graduado e mantido em banho Maria a $35{ }^{\circ} \mathrm{C}$ até seu processamento final. A motilidade e o vigor dos espermatozóides foram analisados sobre lâmina aquecida a $37{ }^{\circ} \mathrm{C}$, em microscópio de contraste de fase com aumentos de 100 e 400 x, respectivamente. $\mathrm{O}$ resultado da motilidade foi fornecido em valores de $0-100 \%$. O vigor foi avaliado em uma escala de $0-5$, classificando-se desta forma a diferença de intensidade de movimento dos espermatozóides. A morfologia foi analisada utilizando-se preparações úmidas, colocando-se uma gota de $10 \mu \mathrm{l}$ da solução de formol salina e espermatozóides sobre lâmina e cobrindo-a com lamínula. As amostras foram observadas em microscópio de contraste de fase sob aumento de $1000 \mathrm{x}$, contando-se 200 espermatozóides. As amostras de sêmen com motilidade acima de 70\%, vigor acima de 3 e patologias totais abaixo de $30 \%$ foram consideradas aptas para serem congeladas com os dois métodos (6).

Após a avaliação microscópica do ejaculado, o diluente tris, gema de ovo e glicerol foi adicionado para obtenção de uma dose inseminante de 20 milhões de espermatozóides, sendo envasada em palhetas de $0,25 \mathrm{ml}$. Obtiveram-se 20 palhetas de cada animal, sendo que 10 foram submetidas ao processo de criopreservação utilizando-se o método automatizado e as outras 10 submetidas ao processo convencional. 
Para a criopreservação pelo método automatizado, utilizou-se o aparelho TK 3000, seguindo-se as instruções do fabricante, com curva de resfriamento de $0,25{ }^{\circ} \mathrm{C} / \mathrm{min}$, duração em torno de 1 hora e 20 minutos, permanecendo a $5{ }^{\circ} \mathrm{C}$ por mais 2 horas. A curva de congelação foi de -20 ${ }^{\circ} \mathrm{C} /$ min até alcançar $-120{ }^{\circ} \mathrm{C}$, posteriormente, as palhetas foram imersas em nitrogênio líquido ($196{ }^{\circ} \mathrm{C}$ ) e, por fim, raqueadas e armazenadas em botijões criogênicos. $\mathrm{Na}$ criopreservação pelo método convencional, as amostras foram mantidas sob refrigeração a $5{ }^{\circ} \mathrm{C}$ por quatro horas. Posteriormente, as amostras foram submetidas a uma pré-congelação por 20 minutos, na qual as palhetas foram mantidas horizontalmente a uma distância de cinco centímetros da lâmina de nitrogênio líquido e, em seguida, foram submersas no nitrogênio e armazenadas no botijão criogênico.

As amostras foram descongeladas um mês após a criopreservação em banho-maria, à $37^{\circ} \mathrm{C}$, por $30 \mathrm{seg}$, e analisadas quanto à cinética de movimento espermático, determinada pelo sistema de análise computadorizada do movimento espermático (CASA). Dois microlitros de sêmen foram colocados na lâmina de leitura (Leja ${ }^{\circledR}$ standard count, SC20. 01.04. B, 20 microns) sendo a amostra avaliada no aparelho modelo IvosUltimate 12 da Hamilton Thorne Biosciences, previamente ajustado (Tabela 1) para análise de sêmen bovino. Os parâmetros de cinética espermática mensurados foram: motilidade progressiva (MP, \%), que corresponde à porcentagem de células movendo-se progressivamente; velocidade de trajeto (VAP, $\mu \mathrm{m} / \mathrm{s}$ ), que corresponde à velocidade média ininterrupta do trajeto da célula; velocidade progressiva (VSL, $\mu \mathrm{m} / \mathrm{s}$ ), que corresponde à velocidade média percorrida em linha reta entre o ponto inicial e final do trajeto; velocidade curvilinear (VCL, $\mu \mathrm{m} / \mathrm{s}$ ), que é a velocidade média mensurada de ponto a ponto do trajeto percorrido pela célula; retilinearidade (STR, \%), que é o valor médio da proporção entre VSL/VAP x 100 e linearidade (LIN, \%), que é o valor médio da proporção entre VSL/VCL x 100. Com a técnica CASA, procurou-se obter fundamentais informações a respeito da cinética dos espermatozóides e correlacionar estes valores com a viabilidade da membrana plasmática e da atividade metabólica das células (7).

Para avaliação da integridade da membrana plasmática, utilizaram-se o diacetato de 6 carboxifluoresceína (C-FDA) e o iodeto de propídeo (IP) conforme a descrição de Harrison \& Vickers (8). A integridade do acrossoma foi avaliada utilizando-se uma conjugação de isotiocianato de fluotresceína - FITC (sonda fluorescente) com lecitina de amendoim (peanut aglutinin - PNA) e IP (9). Para ambos os métodos, uma amostra de sêmen $(10 \mu \mathrm{L})$, foi diluída em uma solução de corante $(30 \mu \mathrm{L})$ e incubada por 10 minutos e protegida da luz. Foram examinadas 200 células espermáticas por lâmina, em microscópio de epifluorescência Nikon E200, sendo classificadas, de acordo com a membrana espermática, em membrana íntegra e membrana lesada. Para a classificação da integridade acrossomal, os espermatozóides foram classificados em quatro categorias, sendo: morto com acrossoma íntegro; morto com acrossoma reagido; vivo com acrossoma íntegro; vivo com acrossoma reagido. Para fins de análise, foram utilizados os percentuais de espermatozóides com membrana íntegra e vivos com acrossoma íntegro.

Tabela 1. Padrões adotados para a análise computadorizada do movimento espermático bovino no aparelho Hamilton Thorne Biosciences (IVOS- Ultimate 12)

\begin{tabular}{lc}
\hline Características & Ajuste \\
\hline Número de imagens adquiridas por campo & 30 \\
Taxa de aquisição das imagens & $60 \mathrm{HZ}$ \\
Contraste mínimo das células & 80 \\
Tamanho mínimo de células & $5 \mathrm{pix}$ \\
Velocidade de trajeto (VAP) & $50 \mu \mathrm{m} / \mathrm{s}$ \\
Retilinearidade (STR) & $70 \%$ \\
Valor de corte VSL para células lentas & $10 \mu \mathrm{m} / \mathrm{s}$ \\
Seleção de campo & Manual \\
\hline
\end{tabular}


Para a análise estatística, utilizou-se o teste Mann Whitney com nível de significância de 5\% (10), sendo realizada com auxílio do programa InStat 3.

\section{RESULTADOS E DISCUSSÃO}

Na Tabela 2 estão descritos os resultados das avaliações seminais realizadas no CASA, não sendo observadas diferenças estatísticas entre as médias dos parâmetros analisados, caracterizando a mesma eficiência entre os dois sistemas de criopreservação.
No sistema automatizado, tem-se o controle constante da temperatura, sendo as curvas de refrigeração e congelação rigorosamente controladas sem a influência da temperatura ambiente. No sistema convencional pode-se ter a influência da temperatura externa, porém como o experimento foi desenvolvido dentro do laboratório, sem variações extremas de temperatura, a curva pode não ter sofrido variações severas, o que pode ter interferido de forma positiva nos resultados, não havendo diferenças estatísticas entre os parâmetros avaliados.

Tabela 2. Média e desvio padrão dos parâmetros motilidade progressiva (MP), velocidade de trajeto (VAP), velocidade progressiva (VSL), velocidade curvilinear (VCL), linearidade (LIN), retilinearidade (STR), utilizando-se o CASA (Computer Assisted Semen Analyzer), $\mathrm{P}<0.05$

\begin{tabular}{lcccccc}
\hline Sistemas & $\begin{array}{c}\text { MP } \\
\%\end{array}$ & $\begin{array}{c}\text { VAP } \\
\mu \mathrm{m} / \mathrm{s}\end{array}$ & $\begin{array}{c}\text { VSL } \\
\mu \mathrm{m} / \mathrm{s}\end{array}$ & $\begin{array}{c}\text { VCL } \\
\mu \mathrm{m} / \mathrm{s}\end{array}$ & $\begin{array}{c}\text { STR } \\
\%\end{array}$ & $\begin{array}{c}\text { LIN } \\
\%\end{array}$ \\
\hline Automatizado & $56,50 \pm 22,25$ & $34,77 \pm 4,25$ & $28,17 \pm 4,25$ & $58,45 \pm 6,85$ & $82,00 \pm 2,31$ & $49,50 \pm 3,32$ \\
Convencional & $57,00 \pm 13,11$ & $25,75 \pm 1,66$ & $23,32 \pm 1,99$ & $63,32 \pm 1,79$ & $82,25 \pm 3,59$ & $50,00 \pm 4,97$ \\
\hline
\end{tabular}

Leite et al. (11), utilizando a máquina TK3000 com 2 horas de tempo de equilíbrio após atingir a temperatura de $5{ }^{\circ} \mathrm{C}$, obtiveram valores semelhantes para os parâmetros de STR e LIN (78,33\% e 47,33\%, respectivamente), porém para a MP, VAP, VSL e VCL obtiveram $26,6 \pm 11,10 \%$; $72,3 \pm 11,16 \mu \mathrm{m} / \mathrm{s} ; 55,19 \pm 6,43 \mu \mathrm{m} / \mathrm{s}$ e $124,75 \pm 20,48$ $\mu \mathrm{m} / \mathrm{s}$, respectivamente, demonstrando, portanto, divergência com os resultados deste trabalho. Devese salientar, contudo, que a programação utilizada para o CASA difere entre os laboratórios e, assim, as comparações devem ser realizadas com cautela.

No trabalho de Crespilho et al. (12), no qual utilizaram uma geladeira digital da Minitube para o resfriamento do sêmen a $5{ }^{\circ} \mathrm{C}$ e posteriormente uma curva negativa de resfriamento com vapor de nitrogênio líquido, os parâmetros do CASA foram similares aos resultados deste trabalho para o MP $(52,5 \pm 9,8 \%)$, STR $(81,3 \pm 3,0 \%)$ e LIN $(55 \pm 7,4 \%)$. Já para os outros parâmetros foram observadas divergências. No atual trabalho, os parâmetros de VAP, VSL e VCL foram inferiores ao do trabalho citado.

$\mathrm{Hu}$ et al. (13), estudando a cinética de movimento de sêmen bovino criopreservado sem equipamento de criopreservação específico, encontraram valores próximos ao do presente trabalho. Foi observado, para os parâmetros de VAP, VSL, VCL, STR e LIN, os valores de $24,59 \pm 1,11$ $\mu \mathrm{m} / \mathrm{s} ; \quad 17,29 \pm 1,12 \quad \mu \mathrm{m} / \mathrm{s} ; \quad 44,14 \pm 1,14 \quad \mu \mathrm{m} / \mathrm{s} ;$ $72,31 \pm 2,34 \%$ e $39,57 \pm 1,32 \%$, respectivamente, ressaltando que os equipamentos de avaliação eletrônica do sêmen foram de marcas diferentes.

As médias e o desvio padrão da integridade de membrana e acrossomo estão apresentadas na Tabela 3, na qual não se observou diferença significativa $(\mathrm{P}>0,05)$ entre os diferentes métodos de congelação. Forero-Gonzalez et al. (14), comparando um sistema automatizado com um convencional, não verificaram diferença estatística entre os sistemas. Esses mesmos autores, trabalhando com sêmen bovino, encontraram $15,58 \%$ e $16,58 \%$ de membranas íntegras e $52,1 \%$ e $49,16 \%$ de acrossoma íntegro para o sistema convencional e automatizado, respectivamente. Os resultados de integridade de membrana plasmática foram inferiores aos resultados do presente estudo $(54,72 \pm 12,55$ e $53,22 \pm 13,22$, respectivamente para o método automatizado e para o convencional), porém não houve diferença no parâmetro de integridade de acrossoma. Estes resultados contradizem a observação feita por Vishwanath \& Shannon (15), que afirmaram que, no sistema automatizado, por congelar um grande número de palhetas, ocorrem consideráveis variações na taxa de congelação individual de cada palheta por ficarem dispostas em diferentes níveis. Esse fato pode não ter ocorrido neste trabalho, pois foi congelado um número 
pequeno de palhetas nos diferentes sistemas, ficando distribuídas de forma homogênea.

Já Purdy (16) afirma que congeladores programáveis são convenientes para a congelação de grandes quantidades de palhetas de sêmen, pelo fato de poderem controlar a taxa de congelação na curva de refrigeração e congelação.

Tabela 3. Média e desvio padrão das avaliações de integridade de membrana plasmática (IMP) e integridade de acrossomo (IA) das amostras congeladas, $\mathrm{P}<0,05$

\begin{tabular}{lcc}
\hline Parâmetros & Método Automatizado & $\begin{array}{c}\text { Método } \\
\text { Convencional }\end{array}$ \\
\hline IMP (\%) & $54,72 \pm 12,55$ & $53,22 \pm 13,22$ \\
IA (\%) & $36,13 \pm 22,20$ & $47,26 \pm 5,74$ \\
\hline
\end{tabular}

Com os resultados deste trabalho é possível escolher o método de criopreservação de sêmen bovino de acordo com as condições do local, disponibilidade da geladeira equilibrada ou do aparelho automatizado. $\mathrm{O}$ aparelho automatizado permite manter a estabilidade de temperatura ao rodar as curvas de resfriamento e congelação e permite a programação de qualquer curva, apesar de o aparelho possuir curvas préestabelecidas. Além disso, tem como vantagem a possibilidade de trabalhar em locais onde não é fornecida energia elétrica, devido à sua funcionalidade com bateria; no entanto, apresenta a desvantagem de ser um aparelho de alto custo.

$\mathrm{O}$ método geladeira/vapor de nitrogênio é de baixo custo, porém não se tem um controle da curva de resfriamento, podendo sofrer variações de temperatura durante a curva de resfriamento e congelação, pois sofrerá a influência da temperatura ambiente, da estabilização da geladeira, qualidade e dimensões da caixa de isopor e nível de nitrogênio. Assim, o sêmen criopreservado poderá ter baixa qualidade caso todas essas variáveis não sejam controladas.

\section{CONCLUSÃO}

Os sistemas de criopreservação de sêmen bovino automatizado e convencional apresentaram a mesma eficiência na proteção aos espermatozóides criopreservados com diluente tris-gema-glicerol. Ambos os sistemas podem ser utilizados para preservação de sêmen bovino de interesse do proprietário que deseja disseminar os benefícios da inseminação artificial na própria propriedade. Desta forma, o método mais adequado para a criopreservação fica a critério do técnico responsável, bem como da realidade de cada propriedade, lembrando sempre que a criopreservação automatizada em equipamento apropriado pode apresentar menor variação e, assim, garantir a repetibilidade dos resultados.

\section{AGRADECIMENTOS}

A Embrapa-Macroprograma 3 e ao CNPq pelo apoio financeiro.

\section{REFERÊNCIAS}

1.Woods EJ, Benson JD, Agca Y, Critser JK. Fundamental cryobiology of reproductive cells and tissues. Cryobiology.[Internet] 2004;48(2):146-56. Disponível em: http://dx.doi.org/10.1016/j.cryobiol.2004.03.002

2.Hammerstedt RH, Graham JK, Nolan JP. Cryopreservation of mammalian sperm: what we ask them to survive. Journal of Andrology. [Internet] 1990;11(1):73-80. Disponível em: http://onlinelibrary.wiley.com/doi/10.1002/j.19394640.1990.tb01583.x/pdf

3.Gilmore JA, Liu J, Woods EJ, Peter AT, Critser JK. Cryoprotective agent and temperature effects on human sperm membrane permeabilities: convergence of theoretical and empirical approaches for optimal cryopreservation methods. Human Reproduction. [Internet] 2000;15(2):335-43. Disponível em: http://humrep.oxfordjournals.org/content/15/2/335.full.pdf

4.Katkov II, Mazur P. Factors affecting yield and survival of cells when suspensions are subjected to centrifugation. Influence of centrifugal acceleration, time of centrifugation, and length of the suspension column in 
quasi-homogeneous centrifugal fields. Cell Biochemistry and Biophysics. 1999;31:231-45.

5. Phelps MJ, Liu J, Benson JD, Willoughby CE, Gilmore JA, Critser JK. Effects of Percoll separation, cryoprotective agents, and temperature on plasma membrane permeability characteristics of murine spermatozoa and their relevance to cryopreservation. Biology of Reproduction. 1999;61:1031-41.

6.Manual para Exame Andrológico e Avaliação de Sêmen Animal. 2 ed. Belo Horizonte: Colégio Brasileiro de Reprodução Animal - CBRA; 1998. 49 p.

7.Gil J, Januskauskas A, Håård M, Håård M, Johanisson A, Söderquist L, et al. Functional Sperm Parameters and Fertility of Bull Semen Extended in Biociphos-Plus ${ }^{\circledR}$ and Triladyl $\mathbb{R}$. Reproduction in Domestic Animals. 2000;35(2):69-77.

8.Harrison RAP, Vickers SE. Use of fluorescent probes to assess membrane integrity in mammalian spermatozoa. Journal of Reproduction and Fertility. 1990;88:343-52.

9.Klinc P, Rath D. Reduction of oxidative stress in bovine spermatozoa during flow cytometric sorting. Reproduction in Domestic Animals. 2007;42:63-7.

10.Sampaio IBM. Estatística aplicada à experimentação animal. Belo Horizonte: Fundação de Ensino e Pesquisa em Medicina Veterinária; 2007. 221 p.
11.Leite TG, Vale Filho VR, Arruda RP, Andrade AFC, Emerick LL, Zaffalon FG, et al. Effects of extender and equilibration time on post-thaw motility and membrane integrity of cryopreserved Gyr bull semen evaluated by CASA and flow cytometry. Animal Reproduction Science. 2010;120:31-8.

12.Crespilho AM, Papa FO, Alberti K, Siqueira Filho ER, A. MJ, Novaes JLC, et al. Eficiência comparativa entre dois diluidores para a congelação de sêmen bovino sobre os padrões de motilidade e integridade de membrana plasmática. Ars Veterinaria. 2006;22(3):229-35.

13.Hu JH, Li QW, Zan LS, Jiang ZL, Na JH, Wang LQ, et al. The cryoprotective effect of low-density lipoproteins in extenders on bull spermatozoa following freezingthawing. Animal Reproduction Science. 2010;117:11-7.

14. Forero-Gonzalez RA, Celeghini ECC, Raphael CF, Andrade AFC, Bressan FF, Arruda RP. Effects of bovine sperm cryopreservation using different freezing techniques and cryoprotective agents on plasma, acrosomal and mitochondrial membranes. Andrologia, 2012; 44:159-154.

15.Vishwanath R, Shannon P. Storage of bovine in liquid and frozen state. Animal Reproduction Science. 2000;62:23-53.

16.Purdy PH. A review on goat sperm cryopreservation. Small Ruminant Research. 2006;63:215-25. 